\title{
A comparative study to evaluate diagnostic accuracy and correlation between saline infusion sonography, hysterosalpingography and diagnostic hysterolaparoscopy in infertility
}

\author{
Arti Tiwari, Beenu Kushwah Singh*, Anuradha Mishra
}

Department of Obstetrics and Gynecology, S. S. Medical College Associated Gandhi Memorial Hospital Rewa, Madhya Pradesh, India

Received: 23 November 2019

Revised: 25 December 2019

Accepted: 31 December 2019

\section{*Correspondence:}

Dr. Beenu Kushwah Singh,

E-mail: drbeenukushwah@gmail.com

Copyright: ( $)$ the author(s), publisher and licensee Medip Academy. This is an open-access article distributed under the terms of the Creative Commons Attribution Non-Commercial License, which permits unrestricted non-commercial use, distribution, and reproduction in any medium, provided the original work is properly cited.

\section{ABSTRACT}

Background: Till date hysterosalpingography (HSG) remains the first-line method to detect tubal patency and to find out any uterine abnormalities in infertile female while diagnostic hysterolaparoscopy (DHL) is considered to be the gold standard method, it is during last decades only that saline infusion sonography (SIS)/ sonohysterography (SHG) has emerged as an efficacious method of checking tubal patency and uterine anatomy as well. The present study aims to compare all three methods viz- SIS, HSG and DHL and to evaluate the correlation between these methods.

Methods: 98 infertile females of age group 18-35 years with normal Hormonal profile without any male factor infertility, were prospectively selected from the outpatient department of obstetrics and gynecology, GMH Rewa, Madhya Pradesh over one year from $1^{\text {st }}$ August 2016 to $31^{\text {st }}$ July 2017.

Results: Diagnostic accuracy (sensitivity and specificity) of SIS was found to be more than HSG for both tubal patency and uterine abnormalities detection. SIS has less numbers of false positive and false negative rates as compared to HSG. DHL was found to be much superior to both SIS and HSG, also detected additional findings in multiple sites like pelvis, tubes and the uterus on the same setting which were missed on SIS and HSG.

Conclusions: SIS may replace HSG as a first step screening method for tubal patency detection, as it has more diagnostic accuracy than HSG and better correlation with DHL and has many advantages and minimal disadvantages as compared to HSG.

Keywords: Diagnostic hysterolaparoscopy, Hysterosalpingography, Infertility, Saline infusion sonography

\section{INTRODUCTION}

Infertility is defined as an inability to conceive a pregnancy following one year of unprotected vaginal intercourse. ${ }^{1}$ It affects about $10-15 \%$ of reproductiveaged couples. $^{2}$ The evaluation of the infertile couple is multifactorial, necessitating physical examination, hormonal testing, imaging modalities, and semen analysis. It is generally considered appropriate to evaluate a couple for causes of infertility after 1 year of failed attempts at conception. However, given the inverse relationship of female fertility with age, it is often recommended that women over 35 years of age be evaluated after 6 months of failure to conceive, and women older than 40 be evaluated immediately. ${ }^{1}$ Evaluation of female partners attempting to conceive requires assessment of the uterus, endometrium and fallopian tubes for anomalies or abnormalities potentially 
preventing normal conception. Diagnostic methods that can be used to assess these structures in female partner are; transvaginal sonography (TVS), saline infusion sonography (SIS)/ sonohysterography (SHG), hysterosalpingography (HSG), diagnostic hysterolaparoscopy (DHL), magnetic resonance imaging (MRI) and computed tomography (CT).$^{2-4}$

HSG is the most widely used technique in the evaluation of infertile females, has a major role in the assessment of the tubes and allows evaluation of the uterine cavity indirectly. ${ }^{5}$ SIS is a more recent addition for tubal patency and intrauterine evaluation. SIS is a simple office procedure which is increasingly being used in preliminary assessment of uterine cavity and fallopian tubes, if used wisely, it will reduce the need for HSG. ${ }^{6}$ It evaluates tubal patency, uterine abnormalities and also tubo-ovarian pathology without the use of radioactive dye. A number of studies have shown a benefit of SIS over HSG in evaluating tubal patency and uterine defects in infertile females, for uterine defects evaluation in recurrent pregnancy loss patients as well as for uterine screening prior to in-vitro fertilization. ${ }^{6-9}$ DHL is considered a gold standard for the evaluation of pelvis and uterine cavity evaluation because it allows direct visualization. DHL can reveal the presence of peritubular adhesions, periadnexal adhesion, tubal pathology and endometriosis in $35-68 \%$ of cases even after normal HSG. ${ }^{2,3,10}$

This is though not without risks involved in the procedure and the anesthesia administered. Laparoscopy combined with hysteroscopy in the same setting (one-step procedure) may obviate the need for HSG in a subset of infertile women. In addition to being diagnostic, this procedure may be utilized for therapy and prognostication, but seeing the associated risks and costs involved it is utilized as a second-line test.

The present study was done to assess the diagnostic accuracy of SIS and HSG in the evaluation of tubal patency and uterine anatomy in infertile females and to compare its result with DHL and to find out the level of correlation between these tests.

\section{METHODS}

It was a prospective comparative study, conducted on 98 infertile females attending the infertility clinic of the department of obstetrics and gynecology of Shyam Shah Medical College and Associated Gandhi Memorial Hospital, Rewa Madhya Pradesh.

\section{Inclusion criteria}

Infertile females aged between 18-35 years with normal hormonal profile and excluding male infertility. The study was conducted over 12 months period from $1^{\text {st }}$ August 2016 to $31^{\text {st }}$ July 2017. After taking informed and written consent, a detailed history, general and systemic examination was done. All females were subjected to SIS, HSG, and DHL on successive days from $6^{\text {th }}$ to $10^{\text {th }}$ day after onset of menstruation in the same cycle. SIS was done by using a pediatric Foleys catheter infusing 20 $\mathrm{ml}$ normal saline, followed by HSG on the next day with the help of water-soluble radioactive dye and followed by DHL on the next day of HSG.

\section{Statistical analysis}

Diagnostic hysterolaparoscopy was considered gold standard, the sensitivity ( $\mathrm{Sn}$ ), specificity (Sf), Positive predictive value (PPV), Negative predictive value (NPV) and likelihood ratio of SIS/SHG and HSG were calculated and Compared with DHL by using Fisher exact test. A Kappa score $(\mathrm{K})$ indicates the level of agreement beyond chance: 0.0-0.2: slight agreement, 0.20.4: fair agreement, 0.4-0.6: moderate agreements, 0.60.8: good agreement, 0.8-1.0: very good agreement. Kappa score for SIS/SHG, HSG and endometrial biopsy with DHL were also calculated.

\section{RESULTS}

On analyzing the baseline characteristics, as shown in Table 1 in the present study, a maximum number of cases belonged to the age group of 26-30 years (52\%), upper lower class $(50 \%)$, had normal BMI $(94 \%)$. Cases of primary infertility were more $(84 \%)$ as compared to secondary infertility (16\%) (Table 1$)$.

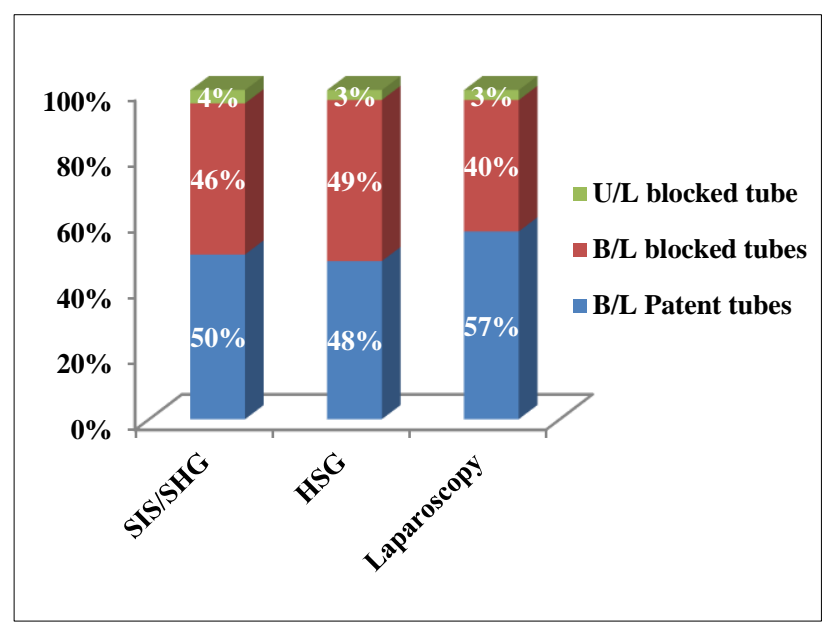

Figure 1: Overall comparison of tubal patency between SIS, HSG, and DHL.

Overall comparison of tubal patency findings of SIS / SHG, HSG and DHL - In present study SIS detected normal tubal findings in 49 patients $(50 \%)$ and abnormal tubal findings in 49 cases $(50 \%)$ out of which bilateral tubal block (other than distal end) in 41 cases (42\%), unilateral blockage other than distal end in $3(3 \%)$ cases, bilateral distal end block (hydrosalpinx) in $4(4 \%)$ cases and unilateral distal block in $1 \%$ cases were seen. 
Table 1: Baseline characteristics of the study population.

\begin{tabular}{|c|c|c|c|}
\hline Baseline characteristics & & No. of infertile females $(n=98)$ & $\%$ \\
\hline \multirow{3}{*}{ Age-wise distribution } & $18-25$ years & 18 & $18 \%$ \\
\hline & 26-30 years & 51 & $52 \%$ \\
\hline & $31-35$ years & 29 & $30 \%$ \\
\hline \multirow{5}{*}{ Socioeconomic status } & Lower & 7 & $7 \%$ \\
\hline & Upper lower & 49 & $50 \%$ \\
\hline & Lower middle & 32 & $33 \%$ \\
\hline & Upper middle & 9 & $9 \%$ \\
\hline & Upper & 1 & $1 \%$ \\
\hline \multirow{4}{*}{ Body mass index (BMI) } & $<18.5$ (underweight) & 2 & $2 \%$ \\
\hline & 18.5-24.9 (normal) & 92 & $94 \%$ \\
\hline & > 24.9-29.9 (overweight) & 4 & $4 \%$ \\
\hline & $\geq 30$ (obese) & 0 & $0 \%$ \\
\hline \multirow{2}{*}{ Type of infertility } & Primary & 82 & $84 \%$ \\
\hline & Secondary & 16 & $16 \%$ \\
\hline
\end{tabular}

Table 2: Correlation for tubal patency between SIS/SHG and DHL ( $\mathrm{n}=98$ cases or 196 tubes).

\begin{tabular}{|llll|}
\hline SIS/SHG & DHL & Blocked tubes & Total \\
\hline Patent tubes & Patent tubes & $3(2 \%)$ & $102(52 \%)$ \\
\hline Blocked tubes & $99(50 \%)$ & $78(40 \%)$ & $94(48 \%)$ \\
\hline Total & $16(8 \%)$ & $\mathbf{8 1}(\mathbf{4 2 \%})$ & $\mathbf{1 9 6}(\mathbf{1 0 0 \%})$ \\
\hline
\end{tabular}

DHL: Diagnostic hysterolaparoscopy, SIS/SHG: Saline infusion sonography/sonohysterography.

Table 3: Correlation for tubal patency between HSG and DHL ( $n=98$ cases or 196 tubes).

\begin{tabular}{|llll|}
\hline \multirow{2}{*}{ HSG } & DHL & Blocked tubes & Total \\
\hline Patent tubes & Patent tubes & $5(2 \%)$ & $97(49 \%)$ \\
\hline Blocked tubes & $92(47 \%)$ & $76(39 \%)$ & $99(51 \%)$ \\
\hline Total & $23(12 \%)$ & $\mathbf{8 1 ( 4 1 \% )}$ & $\mathbf{1 9 6 ( 1 0 0 \% )}$ \\
\hline
\end{tabular}

DHL: Diagnostic hysterolaparoscopy, HSG: Hysterosalpingography.

On HSG abnormal tubal findings were found in 51 cases $(52 \%)$ out of total 98 cases in which bilateral and unilateral tubal blockage other than distal end was seen in 45 cases $(46 \%)$ and $3(3 \%)$ respectively and bilateral distal end block in $3(3 \%)$ cases. While laparoscopy detected bilateral patent tubes in $56(57 \%)$ cases, bilateral tubal blockage in $39(40 \%)$, right tubal blockage in 1 $(1 \%)$ and left tubal blockage in $2(2 \%)$ cases out of 98 (100\%) cases (Figure 1).

\section{Correlation for tubal patency between SIS, HSG and DHL}

On statistical analysis of (Table 2 and 3) by using twosided Fisher exact test, SIS and HSG both has P-value < 0.0001 for tubal patency detection, Thereby it was found to be highly significant, also Row/column (SIS or HSG with DHL) association is statistically significant. Sensitivity and specificity of SIS for tubal findings calculated to be $86 \%$ and $96.8 \%$, whereas for HSG $80 \%$ and $93.8 \%$ respectively as shown in Table 2 and 3 (taking sensitivity and specificity of DHL 100\%) (Table 2).

Kappa (correlation coefficient) for SIS with DHL for tubal patency detection calculated to be $0.805 \pm 0.042$, while for HSG, kappa is $0.715 \pm 0.049$ that means strength of agreement between SIS and DHL for tubal patency is considered to be 'very good' as compared to HSG, calculated strength of agreement of HSG with DHL is found to be only 'good' (Table 3).

\section{Overall comparison of uterine findings in SIS, HSG, and $\mathrm{DHL}$}

In present study SIS/SHG showed abnormal uterine findings in 26 (27\% cases) out of $98(100 \%)$ as in Table 4 , in which adhesions were found in $8(9 \%)$ cases, polyp in $5 \%$, fibroid in $4 \%$, small uterus, endometrium thinning, endometrial hyperplasia and septum in $3 \%, 3 \%, 2 \%$ and $1 \%$ cases respectively. As shown in Table 5, HSG detected abnormal uterine findings in $11 \%$, in which 
distorted cavity (polyp and fibroma) in 5\%, filling defects (adhesions) in 5\% and septate/ bicornuate uterus in $1 \%$ cases respectively. DHL detected normal uterine findings in $56(57 \%)$ and abnormal uterine findings in $42(43 \%)$ cases. Adhesions were found in $12 \%$, fibroid in $8 \%$, scarred atrophic endometrium in $8 \%$, polyp in $5 \%$, strawberry spots on uterine wall in $4 \%$, small uterus in $3 \%$, septum and multiple calcified lesions in $2 \%$ and $1 \%$ respectively (Table 4,5$)$.

Table 4: Correlation of uterine findings between SIS/SHG and hysteroscopy $(n=98)$.

\begin{tabular}{|llll|}
\hline SIS / SHG & Hysteroscopy & & Total \\
\hline Normal & Normal & Abnormal & $72(73 \%)$ \\
\hline Abnormal & $56(57 \%)$ & $16(16 \%)$ & $26(27 \%)$ \\
\hline Total & $0(0 \%)$ & $26(27 \%)$ & $\mathbf{9 8 ( 1 0 0 \% )}$ \\
\hline
\end{tabular}

SIS/SHG: Saline infusion sonography/sonohysterography.

Table 5: Correlation of uterine findings between HSG and hysteroscopy $(n=98)$.

\begin{tabular}{|llll|}
\hline \multirow{2}{*}{ HSG } & Hysteroscopy & & Total \\
\hline Normal & Normal & Abnormal & $87(89 \%)$ \\
\hline Abnormal & $55(56 \%)$ & $32(33 \%)$ & $11(11 \%)$ \\
\hline Total & $1(1 \%)$ & $10(10 \%)$ & $\mathbf{9 8 ( 1 0 0 \% )}$ \\
\hline
\end{tabular}

HSG: Hysterosalpingography.

Table 6: Additional findings in laparoscopy $(\mathrm{n}=98)$ (findings occurs alone or in combinations).

\begin{tabular}{|lll|}
\hline Findings in laparoscopy & No. of cases $(\mathbf{n}=\mathbf{9 8})$ & \% \\
\hline No additional findings & 36 & $37 \%$ \\
\hline Additional findings & 62 & $63 \%$ \\
\hline Adhesion (peritubal/periovarian/perihepatic) & 28 & $29 \%$ \\
\hline Thickened tubes & 15 & $15 \%$ \\
\hline Brownish lesions (suggestive of endometriosis) & 13 & $13 \%$ \\
\hline White tubercles (suggestive of genital tuberculosis) & 11 & $8 \%$ \\
\hline Beaded tubes & 8 & $7 \%$ \\
\hline Polycystic ovary & 7 & $6 \%$ \\
\hline Fimbrial agglutination & 6 & $5 \%$ \\
\hline Distended tubes (hydrosalpinx) & 5 & $5 \%$ \\
\hline Fibroid / myoma & 5 & $2 \%$ \\
\hline Arcuate uterus & 2 & $1 \%$ \\
\hline Bicornuate uterus & 1 & $7 \%$ \\
\hline
\end{tabular}

\section{Correlation of uterine findings between SIS, HSG and DHL}

In present study by using two-sided Fisher exact test on Table 4 and 5, P-value of SIS and HSG for uterine finding detection comes out $<0.0001$, which is extremely significant. The row/ column association (SIS or HSG and DHL) is statistically significant. Sensitivity and specificity of SIS for uterine finding detection is calculated to be $100 \%$ and $61.90 \%$ whereas for HSG $98 \%$ and $24 \%$ respectively (taking sensitivity and specificity of DHL $100 \%$ ). In the present study Kappa value for uterine finding, detection is calculated to be $0.650 \pm 0.075$ for SIS and $0.243 \pm 0.075$ for HSG in relation to DHL. Strength of agreement for uterine finding detection is found to be 'good' between SIS and and DHL, while for HSG and DHL is found to be 'fair'.

\section{Additional findings on $\mathrm{DHL}$}

As shown in Table 6, in present study laparoscopy detected additional findings in $63 \%$ cases, out of which maximum cases of adhesions detected in $29 \%$, thickened tubes in $15 \%$, finding suggestive of endometriosis and tuberculosis in $13 \%$ and $11 \%$ respectively.

\section{DISCUSSION}

In the present study we took 98 infertile females, maximum number of patients $(52 \%)$ belonged to 26 to 30 
years of age, Similarly, Yildizhan et al, in their study on infertility studied patients in range of 21-38 years. ${ }^{11}$ They found maximum patients in the age group of 25-30 years which is almost comparable to the present study.

In the Indian studies, Barati et al had patients age in a range of $19-48$ years with a mean age of 31 years age. ${ }^{12}$ Sahu et al, had a maximum incidence $(54.62 \%)$ of infertility in $<30$ years of age. These results were also similar to the present study. ${ }^{13}$

\section{Correlation of tubal patency findings between SIS/SHG, HSG and DHL}

In present study we took 98 cases as 196 tubes, SIS/SHG and DHL both showed tubal patency in 99 tubes (true positive) and tubal blockage (true negative) in 78 tubes while SIS/SHG showed 16 tubes blocked which were detected patent during laparoscopy (false positive) and 3 tubes were patent in SIS/SHG but blocked during laparoscopy (false negative). HSG showed a greater number of false positive and false negative as compared to SIS/SHG. In present study sensitivity and specificity of SIS were more $86 \%$ and $97 \%$ as compared to HSG $80 \%$ and $94 \%$ respectively. PPV and NPV were more for SIS/SHG (97\% and 83\%) as compared to HSG (95\% and $77 \%$ ). Kappa's value of agreement between SIS/SHG and laparoscopy was more than HSG and laparoscopy so SIS/SHG agreed with laparoscopy in more cases than HSG. So, SIS/SHG found to be a better procedure than HSG for tubal patency detection and closer to laparoscopic findings.

In a study done by Agrawal $\mathrm{R}$ et al, also calculated sensitivity and specificity of SIS (89\% and 75\%), and PPV and NPV for SIS/SHG (96\% and 47\%) and for HSG sensitivity and specificity (94\%, 83\%), and PPV and NPV were $97 \%$ and $66 \%$ respectively for tubal patency detection, and concluded that diagnostic accuracy of SIS/SHG better than HSG similar to present study. ${ }^{5}$ In a similar study, Singhal A et al, also calculated sensitivity (97\%), specificity (87.5\%) and PPV (94\%) for SIS/SHG in relation to laparoscopy for tubal patency. ${ }^{7}$ Hajishafiha $M$ et al in their study concluded that HSG detected the high rate of false-positive and false-negative as compared to SIS/SHG, not due to actual tubal block but are due to a transient spasm. ${ }^{8}$ Similarly, in our study, HSG detected falser positive and false negative. Malik B et al, and Razk et al found similar results as the present study and observed better sensitivity and specificity of SIS/SHG for tubal patency than HSG. ${ }^{9,14}$

\section{Correlation of uterine findings of SIS/SHG and HSG with hysteroscopy and comparison of SIS/SHG with HSG for uterine finding}

In present study SIS/SHG showed abnormal uterine findings in $26(27 \%)$ cases, HSG in $11(11 \%)$ cases and hysteroscopy in $42(43 \%)$ cases respectively. One case in HSG showed abnormal uterine finding which appeared normal in hysteroscopy (false positive), there was no false positive in SIS/SHG. in present study sensitivity, specificity, PPV, NPV of SIS/SHG (100\%, 62\%, 78\%, $100 \%$ respectively) for uterine findings detection were more than HSG $(98 \%, 24 \%, 63 \%, 91 \%$ respectively) in relation to hysteroscopy. SIS/SHG had good agreement with hysteroscopy for uterine findings in comparison to HSG.

In a similar study done by Yeshita $\mathrm{P}$ et al, calculated sensitivity and specificity for SIS (98\% and 89\%) and PPV and NPV for SIS/SHG (98\% and $89 \%$ ) respectively for uterine findings. ${ }^{15}$ Uchanna $\mathrm{CA}$ et al also calculated sensitivity and specificity for SIS/SHG, 82\%, and 94\% and for HSG sensitivity and specificity were $58 \%$ and $26 \% .{ }^{16}$ The above study showed sensitivity and specificity of SIS/SHG were more than HSG similar to the present study.

In a similar study done by Meenakshi B et al, showed Sensitivity and specificity for HSG $(50 \%$ and $98 \%)$ and PPV and NPV (76.9\% and $88.5 \%$ ) for uterine findings. ${ }^{17}$

So, SIS can be used as a simple, cost-effective diagnostic tool in the evaluation of infertility, for both in detection of tubal patency and for uterine findings with better diagnostic accuracy than HSG. In a study done by Dasan TA et al diagnostic accuracy of SIS was found to be superior than HSG in detecting tubal patency as well as evaluation of uterine and ovarian factors of infertility similar to the present study. ${ }^{18}$ A study done by Vinita Singh et al concluded that in a low resources country like in India, SIS can prove to be a useful tool in the initial workup of infertile females with better compliance, low cost and better results in a single visit. ${ }^{19}$

In the present study DHL also detected additional findings in $63 \%$ cases, out of which maximum cases of adhesions, thickened tubes detected followed by findings suggestive of endometriosis and tuberculosis. In a similar study done by Mehta AV et al concluded that DHL is an effective and safe tool in comprehensive evaluation of infertility, particularly for detecting peritoneal endometriosis, adnexal adhesions, and septate uterus. ${ }^{20}$ These are correctable abnormalities that are unfortunately missed by usual imaging procedures. it can detect various structural abnormalities in multiple sites like pelvis, tubes, and uterus in the same setting with normal ovulation and seminogram. When done by experienced hands and with proper selection of patients, DHL can be considered as a definitive investigative procedure for the evaluation of female infertility.

\section{CONCLUSION}

Results of SIS/SHG agrees with diagnostic hysterolaparoscopy (DHL) in a greater number of cases as compare to HSG. So, SIS/SHG can replace HSG as a first step screening method for tubal patency detection in infertile women, as it can also detect various uterine 
findings, is a cost-effective outpatient procedure, is more efficient (has diagnostic accuracy more than HSG) and has many advantages and minimal disadvantages as compared to HSG. Diagnostic HYSTERO laparoscopy is no doubt much superior than SIS/SHG and HSG, therapeutic intervention is also possible at the same time. It is very accurate and can detect various structural abnormalities at multiple sites like pelvis, tubes and the uterus in the same setting which are missed by other imaging modalities. But it is not free from complications related to anesthesia and surgery. Therefore, seeing the benefits, SIS can very well be adopted as a first-line day care procedure to evaluate female infertility. To conclude SIS/SHG is an easy, safe, acceptable outpatient procedure and can be performed while doing the first routine ultrasonography of infertile females. It has no allergic reactions and avoid harmful radiation exposure to patient as in HSG. It has sensitivity, specificity, PPV and NPV higher than HSG for both tubal patency detection and abnormal uterine finding detection in cases of infertility.

\section{Funding: No funding sources}

Conflict of interest: None declared

Ethical approval: The study was approved by the Institutional Ethics Committee

\section{REFERENCES}

1. McLaren JF. Infertility evaluation. Obstet Gynecol Clin North Am. 2012;39:453-63.

2. Mehta AV, Modi AP, Raval BM, Munshi SP, Patel SB. Role of diagnostic hysterolaparoscopy in the evaluation of infertility. Int J Reprod Contracept Obstet Gynecol. 2016;5(2):437-40.

3. Jahan S. Role of laparoscopy in infertility: review article. Birdem Med J. 2012;2:99-103.

4. El-Mazny A, AbouSalem N, El-Sherbiny W, Saber W. Outpatient hysteroscopy: a routine investigation before assisted reproductive techniques? Fertil Steril. 2011;95:272-6.

5. Agrawal R, Shrivastava D. Role of hysterosalpingography in the evaluation of tubal factors and its comparison with sonosalpingography. Int $\mathrm{J}$ Reprod Contracept Obstet Gynecol. 2017;1:121-6.

6. Kulkarni NN, Patel R, Patel NR. Comparative study of SHG VS HSG for tubal patency test. Int J Reprod Contracept Obstet Gynecol. 2016;5(10):3300-3.

7. Hajishafiha M, Zobairi T, Zanjani VR. Diagnostic value of sonohysterography in the determination of fallopian tube patency as an initial step of routine infertility assessment. J Ultra Med. 2009;28:1671-7.

8. Arpana S, Konpal A, Rakesh K. Comparison of transvaginal sonosalpingography to chromolaparoscopy for evaluation of tubal patency in infertility patients. IOSR-JDMS. 2016;15:47-9.
9. Malik B, Patil S, Boricha BG, Kurkal N, Choudhry M. A comparative study of the efficacy of sonosalpingography and hysterosalpingogram to test the tubal patency in all women with primary and secondary infertility. Ultrasound Quart. 2014;30:139-43.

10. Shah SJ, Shah AC, Dwivedi YN. Study of combined laparoscopic and hysteroscopic findings in 100 cases of infertility. NHL J Med Sci. 2014;3:68-71.

11. Yildizhan B, Durmusoglu F, Uygur M, Erenus M. A new technique for the diagnosis of fallopian tube patency by hysteroscopy with ultrasound compared with hysterosalpingography in infertile women. Archi Gynaecol Obstet. 2009;280:543-7.

12. Barati M, Zargar M, Saramasihi. Office hysteroscopy in infertility. Int J Fert Ster. 2009;3:17-20.

13. Sahu L, Tempe A, Gupta S. Hysteroscopic evaluation in infertile patients: a prospective study. Int J Reprod Contracept Obstet Gynecol. 2012;1:37-41.

14. Razek M, Shawky M. The safety and acceptability of saline infusion sonography versus hysterosalpingography for evaluation of tubal patency in infertile women. Middle East Fertil Soc J. 2015;20:108-13.

15. Pujar Y, Sherigar B, Patted S, Desai B, Dhumale H. Comparative evaluation of saline infusion sonohysterography and hysterolaparoscopy for diagnosis of uterine cavity abnormalities and tubal patency in infertility: a one-year cross sectional study. South Asian Fed Obstet Gynecol. 2010;2:133-5.

16. Acholonu Jr UC, Silberzweig J, Stein DE, Keltz M. Hysterosalpingography versus sonohysterography for intrauterine abnormalities. JSLS. 2011;15:471-4.

17. Meenakshi BC, Pinkey LS, Smiti N, Van M. Hysterosalpingography versus hysteroscopy: role in assessment of uterine factors during infertility workup. JP IJIFM. 2013;4:79-82.

18. Dasan TA, Basawaraj NG. A comparative study of saline-infused sonohysterography and conventional hysterosalpingography in the evaluation of female infertility. West Afr J Radio. 2016;23:124-9.

19. Singh V, Mishra B, Sinha S, Agrawal S, Thakur P. Role of saline infusion sono hysterography in infertility evaluation. J Hum Reprod Sci. 2018;11(3):236-41.

20. Mehta AV, Modi AP, Raval BM, Munshi SP, Patel SB. Role of diagnostic hysterolaparoscopy in the evaluation of infertility. Int J Reprod Contracept Obstet Gynecol. 2016;5:437-40.

Cite this article as: Tiwari A, Singh BK, Mishra A. A comparative study to evaluate diagnostic accuracy and correlation between saline infusion sonography, hysterosalpingography and diagnostic hysterolaparoscopy in infertility. Int J Reprod Contracept Obstet Gynecol 2020;9:669-74. 